\title{
Correction to: Predictive Policing in 2025: A Scenario
}

Kevin Macnish, David Wright, and Tilimbe Jiya

\section{Correction to:}

Chapter "Predictive Policing in 2025: A Scenario" in:

H. Jahankhani et al. (eds.), Policing in the Era

of AI and Smart Societies, Advanced Sciences

and Technologies for Security Applications, https://doi.org/10.1007/978-3-030-50613-1_9

Chapter (9), "Predictive Policing in 2025: A Scenario" was previously published non-open access. It has now been changed to open access under a CC BY 4.0 license and the copyright holder updated to 'The Author(s)'. The book has also been updated with this change. 